\title{
THE POTENTIAL OF REACTIVELY RF SPUTTERED ZnO THIN FILMS FOR THE FABRICATION OF MICROWAVE FILTERS
}

\author{
A. T. KOLLIAS, E. D. TSAMIS and J. N. AVARITSIOTIS* \\ Department of Electrical and Computer Engineering, \\ National Technical University of Athens, 9, Iroon Polytechniou St. Zografou, \\ Athens, 15773, Greece
}

(Received 20 April 2000; In final form 25 April 2000)

The piezoelectric properties of reactively sputtered $\mathrm{ZnO}$ thin films deposited on glass and silicon substrates were studied in order to assess their potential for the construction of RF overmoded filters. Films of high crystallographic orientation $\{002\}$, as shown by XRD measurements and SEM observations, and high value of $k_{\mathrm{eff}}^{2}$, calculated with the aid of the BVD model, were obtained after the optimization of the deposition conditions, with highly repetitive properties. Simple devices were designed and constructed on silicon substrates which showed a quality factor of 1000 without the use of a Bragg acoustic reflector, and a temperature drift of $-30 \mathrm{ppm} /{ }^{\circ} \mathrm{C}$.

Keywords: Zinc oxide; Overmoded resonator; Piezoelectric filters; BAW

\section{INTRODUCTION}

Zinc oxide $(\mathrm{ZnO})$ thin films are extremely promising as electromechanical elements for use with micromechanical structures given that $\mathrm{ZnO}$ is a semiconductor with a high piezoelectric coupling factor.

$\mathrm{ZnO}$ films have up to now been used mainly in sensing applications. For example, Itoh and Suga [1] have reported on the development of

*Corresponding author. e-mail: abari@cs.ntua.gr 
a force sensor for atomic force microscopy (AFM) using $\mathrm{ZnO}$ films deposited by r.f. magnetron sputtering. Deschanvres et al. [2] have investigated the piezoelectric characteristics of $\mathrm{ZnO}$ films, deposited by CVD, as sensors. Blorn et al. [3] has reported on the application of $\mathrm{ZnO}$ as a micromechanical actuator at low frequencies. They have shown that the fabrication of an actuator as a MOS device produces a piezoelectric actuator suitable for use at low frequencies, since the insulating $\mathrm{SiO}_{2}$ layer reduces electrical leakage. There are many applications for piezoelectric microactuators such as microoptics [4], linear stepper motors [5], scanning mirror drives [6], microsurgery [7, 8], scanning force microscopy [9], ultrasonic sensor for gas flow measurement [10] and micromechanical cantilevers [11] and flexural actuators [12].

The use of $\mathrm{ZnO}$ as a piezoelectric transducer has also been reported for SAW resonators [13] and BAW resonators [14]. Due to wireless communications exponential growth the last years there is increased interest in on-chip thin film resonators (TFRs) for applications in high frequency filters. In particular the majority of heterodyning communication transceivers rely heavily upon the high $Q$ of SAW and BAW mechanical resonators to achieve adequate frequency selectivity and low phase noise and stability [15]. At present the aforementioned devices are off chip components consuming a sizeable portion of the total transceiver subsystem area. Also these required components are a bottleneck to singe chip transceiver fabrication. The construction of TFRs is compatible with the rest of silicon semiconductor processing steps and has the potential to integrate on chip the functions of the aforementioned off chip components $[29,28]$.

\section{ZnO THIN FILM DEPOSITION}

$\mathrm{ZnO}$ films were prepared using an r.f. sputtering system which was equipped with a horizontal cathode. A detailed description of the sputtering system may be found elsewhere [16]. Typically, the system was pumped down to a base pressure of $1 E-6$ mbar before introducing the process gases $\left(\mathrm{Ar}_{2} / \mathrm{O}_{2}\right)$. The substrate temperature varied between room temperature and $400^{\circ} \mathrm{C}$. $\mathrm{ZnO}$ films were deposited onto 
glass and $\{100\}$ silicon wafers covered with a $\mathrm{Zn}$ bottom electrode, which was also deposited by r.f. sputtering. ZnO film deposition followed. It is well known that the physical properties of sputtered films are influenced by growth parameters [17-19], such as substrate temperature, sputter gas composition and pressure. Also deposition parameters affect film resistivity [20]. With this in mind, we have optimized sputtering conditions, such as the partial gases pressures temperature and the r.f. input power. Typical sputtering conditions for $\mathrm{Zn}$ and $\mathrm{ZnO}$ are listed in Table $\mathrm{I}$. The sputtering targets are obtained by casting $\mathrm{Zn}$ (purity $99.99 \%$ ) on $\mathrm{Cu}$ target holders. With these conditions the growth rate is of the order $125 \AA$ per min. $\mathrm{ZnO}$ films with thicknesses ranging from 1 to $2 \mu \mathrm{m}$ were deposited. The substrate temperature was varied between room temperature and $400^{\circ} \mathrm{C}$. For low and high substrate temperatures the piezoelectric activity of the films degrades appreciably. Below $100^{\circ} \mathrm{C}$ the films exhibit very poor $c$-axis orientation. In general, the degree of orientation is strongly influenced by the substrate temperature [21].

The $\mathrm{ZnO}$ films require upper and bottom electrodes in order for them to be used as piezoelectric devices. Each electrode consisted of a $\mathrm{Zn}$ layer of thickness between 0.1 and $0.3 \mu \mathrm{m}$. While the bottom electrode run all over the sample surface the top $\mathrm{Zn}$ electrodes were patterned using metal contact masks to enable individual dots of various diameters, between $100 \mu \mathrm{m}$ and $500 \mu \mathrm{m}$, to be made. Provision was taken so that close to the individual dots a much larger area ground electrode was deposited. The structure of the final device is shown in Figure 1. This large area ground electrode functions as a low impedance ac conductive path to the bottom electrode to minimize parasitic effects [26].

TABLE I $\mathrm{ZnO}-\mathrm{Zn}$ deposition parameters

\begin{tabular}{lccc}
\hline Sample no. & $\# 1$ & $\# 2$ & $\# 3$ \\
\hline Temp $\left({ }^{\circ} \mathrm{C}\right)$ & Room temp & 200 & 300 \\
Total Pressure (mTorr) & & $3 E-3$ & \\
Time (hours) & 2.5 & \\
Cathode current (A) & 0.26 & \\
H.T. (kV) & 1.4 & \\
DC Potential (Volt) & 220 & \\
$\mathrm{Ar}_{2} / \mathrm{O}_{2}$ (ZnO desposition) & $20(\mathrm{ml} / \mathrm{min}) / 30(\mathrm{ml} / \mathrm{min})$ & \\
\hline
\end{tabular}




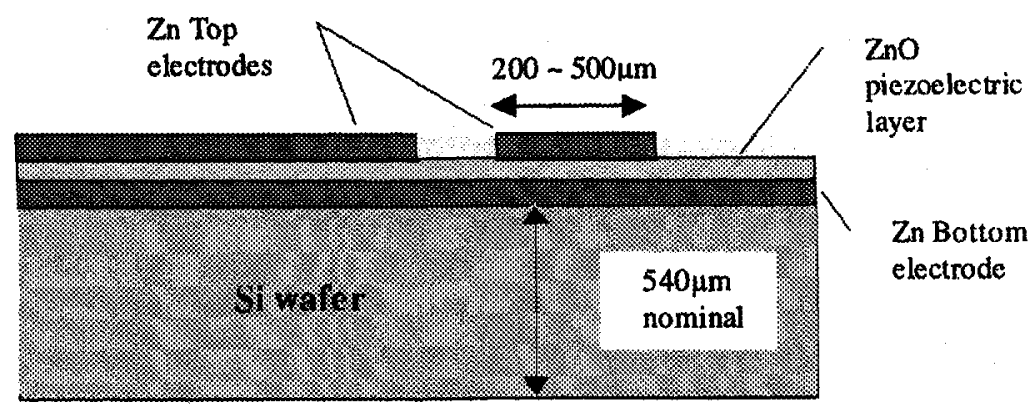

(a)

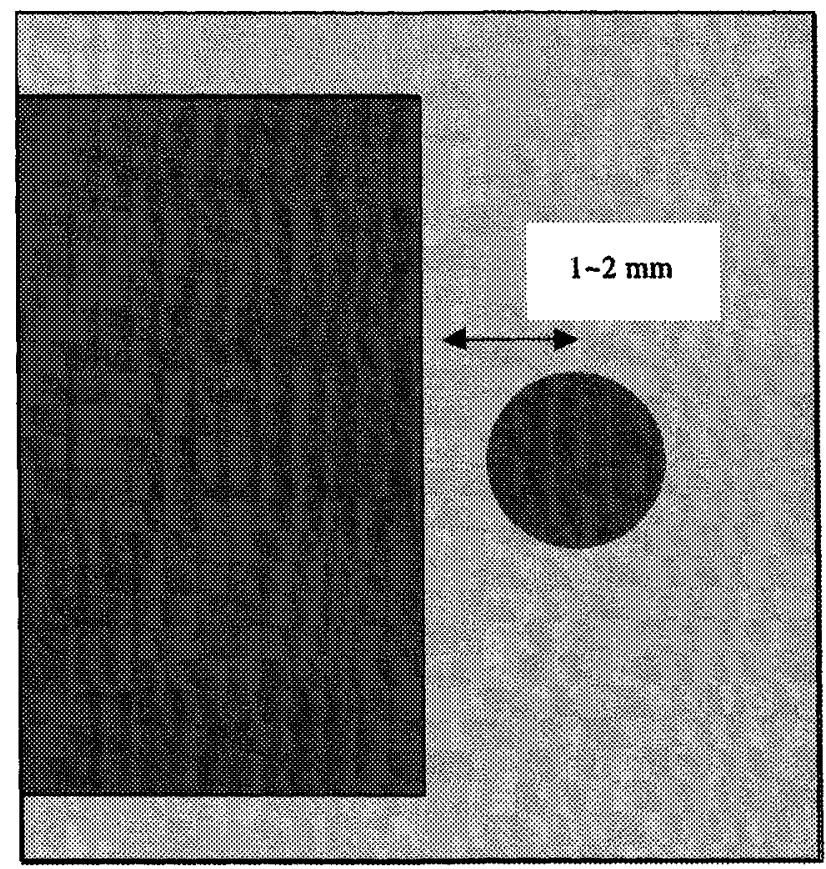

(b)

FIGURE 1 Cross section (a) and top view (b) of the device used for piezoelectric film high frequency measurements (Not in scale).

\section{FILM CRYSTALLOGRAPHIC ORIENTATION}

Sputtered $\mathrm{ZnO}$ thin films are generally polycrystalline with a $c$-axis preferred orientation [10]. The intensity of the $\{002\}$ peak is a direct 
indication of the $c$-axis orientation perpendicular to the substrate surface. Film orientation is shown by XRD spectra in Figures $2-4$ for films grown at different substrate temperatures. The $\{002\}$ peak intensity increased by a factor of more than two when the substrate temperature was increased. The crystallinity improved as the growth temperature increased, as shown by the X-ray diffraction peak intensity and its width. The microstructure of the $\mathrm{ZnO}$ films was observed using scanning electron microscopy (Fig. 5). This observation showed that the structure is dense and minimal porosity. No cracks or voids were present. The oriented films have a

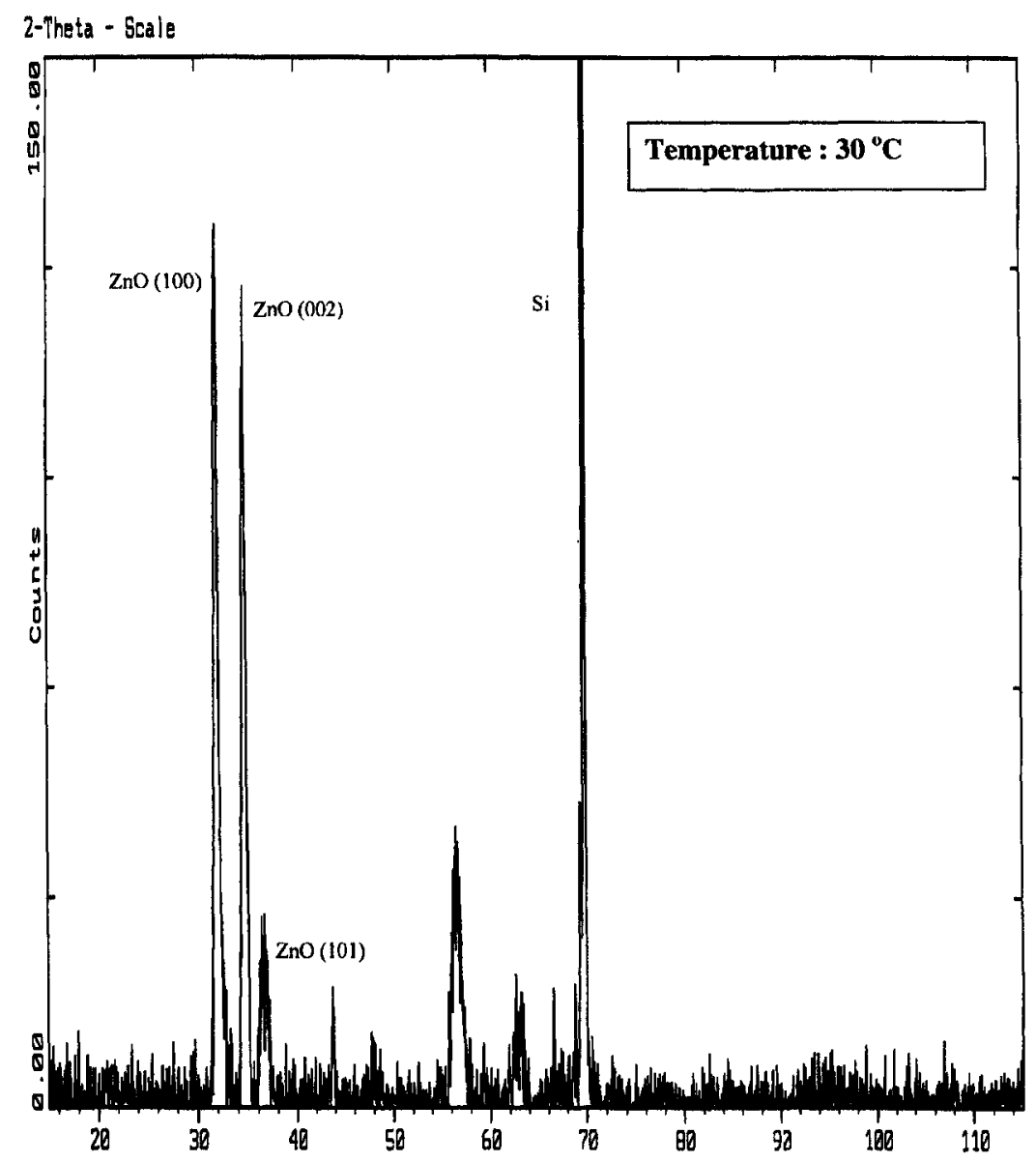

FIGURE 2 XRD spectra obtained from $\mathrm{ZnO}$ film deposited at $30^{\circ} \mathrm{C}$. 


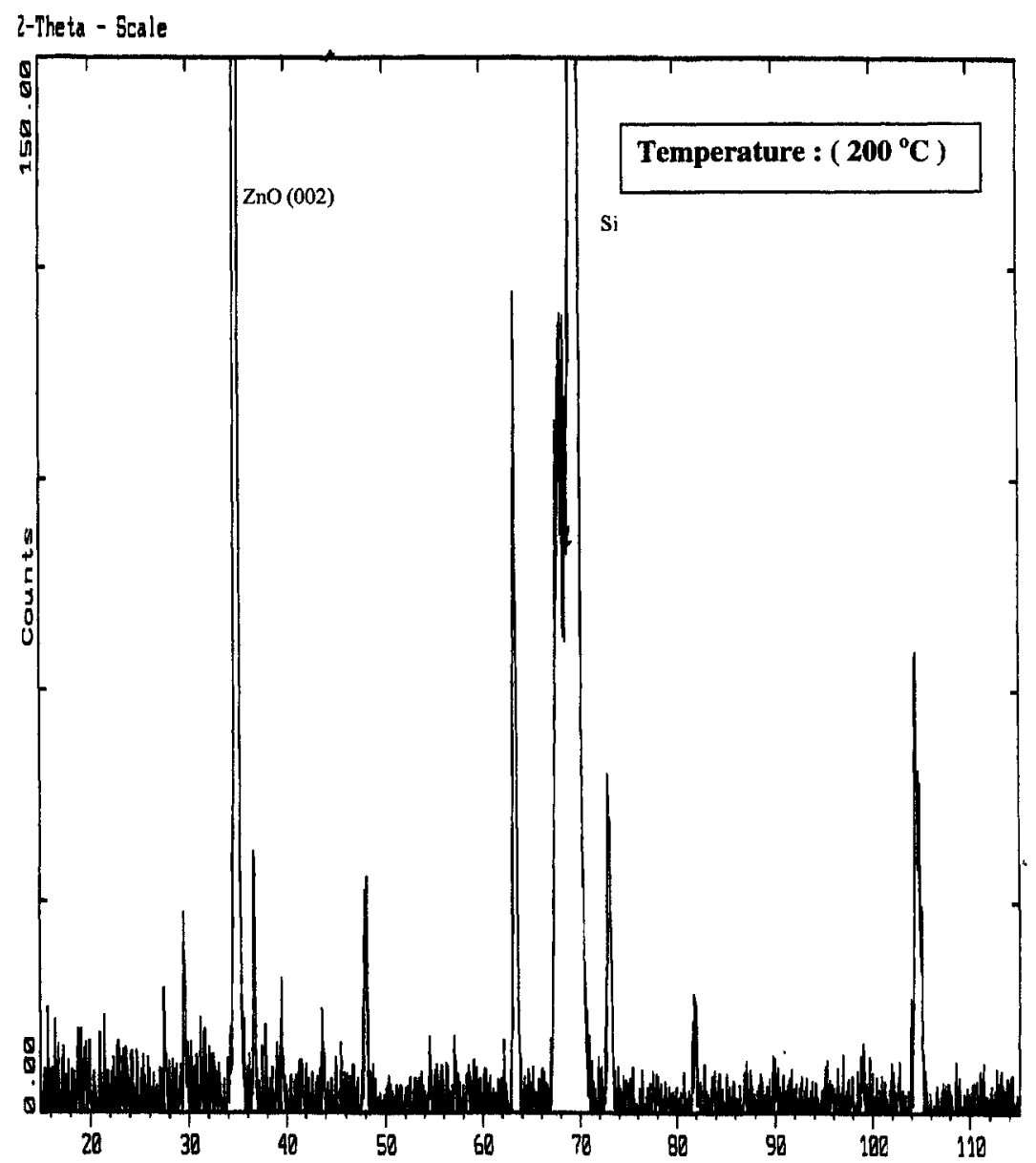

FIGURE 3 XRD spectra obtained from $\mathrm{ZnO}$ film deposited at $200^{\circ} \mathrm{C}$.

columnar structure with columns perpendicular to the substrate. The primary effect of a change in composition from an oxygendeficient material to stoichiometric $\mathrm{ZnO}$ is a preferred $\{002\}$ orientation. Since no other peaks besides the $\{002\}$ orientation where present at $200^{\circ} \mathrm{C}$ deposited films these are thought to be nearly stoichiometric.

An increase in the preferred $\{002\}$ orientation with increasing $\mathrm{O}_{2}$, pressure in the $\mathrm{Zn} / \mathrm{ZnO}$ film has been observed. It may be 


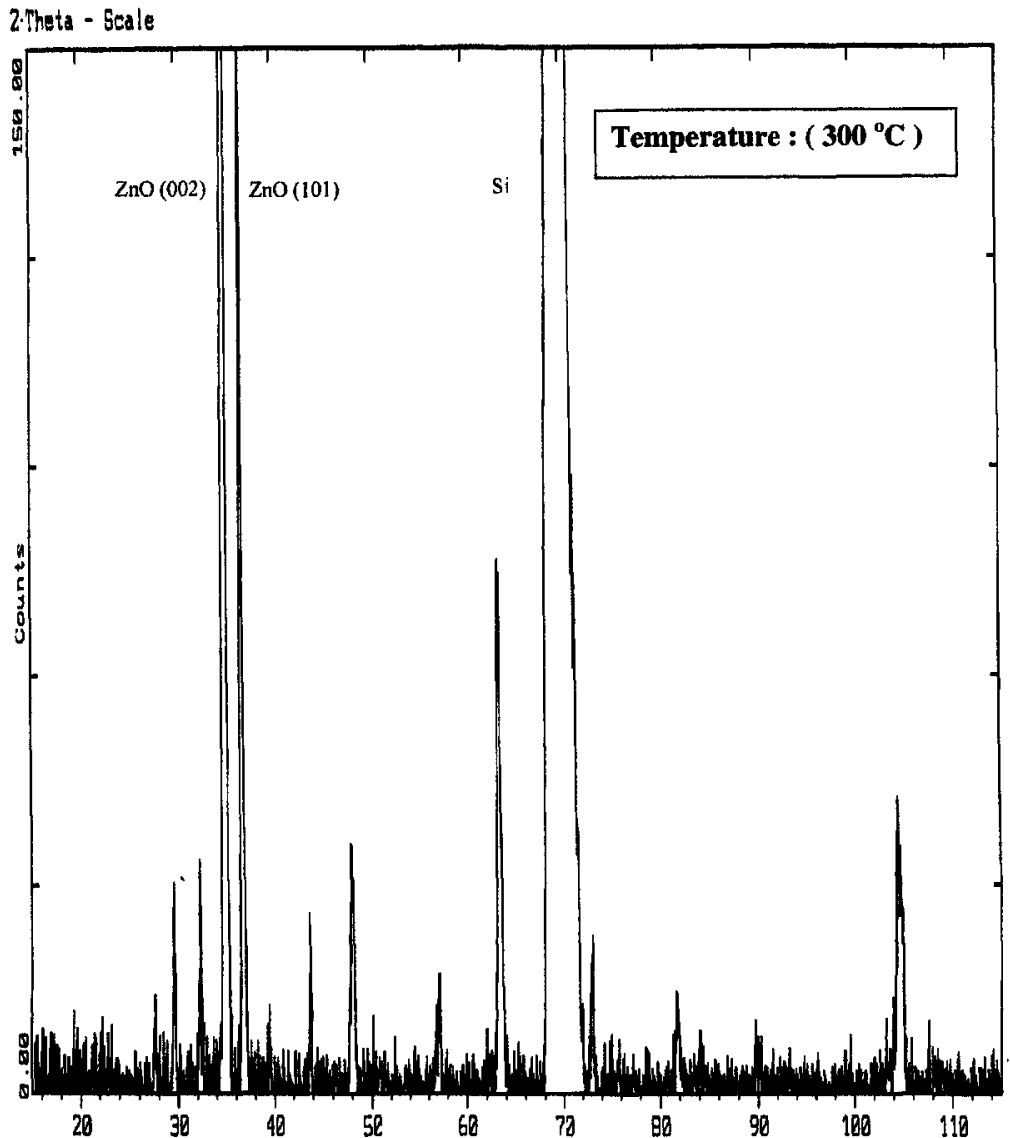

FIGURE 4 XRD spectra obtained from $\mathrm{ZnO}$ film deposited at $300^{\circ} \mathrm{C}$.

argued that the variation in the $\mathrm{ZnO}$ crystal structure, is due to the competing effects of ion bombardment causing film amorphization and the increased oxygen content in the sputtering gas mixture causing improved crystallinity and a preferred $\{002\}$ orientation. The resputtering of the films by high-energy neutral oxygen atoms is thought to be dominant because the sputtering pressure was set to $3 E-3 \mathrm{~m}$ Torr in this study. Therefore, the observed decrease in the preferred $\{002\}$ orientation with decreasing $\mathrm{Ar}_{2} / \mathrm{O}_{2}$, ratio can be explained by the resputtering effect of the neutral oxygen [22]. 


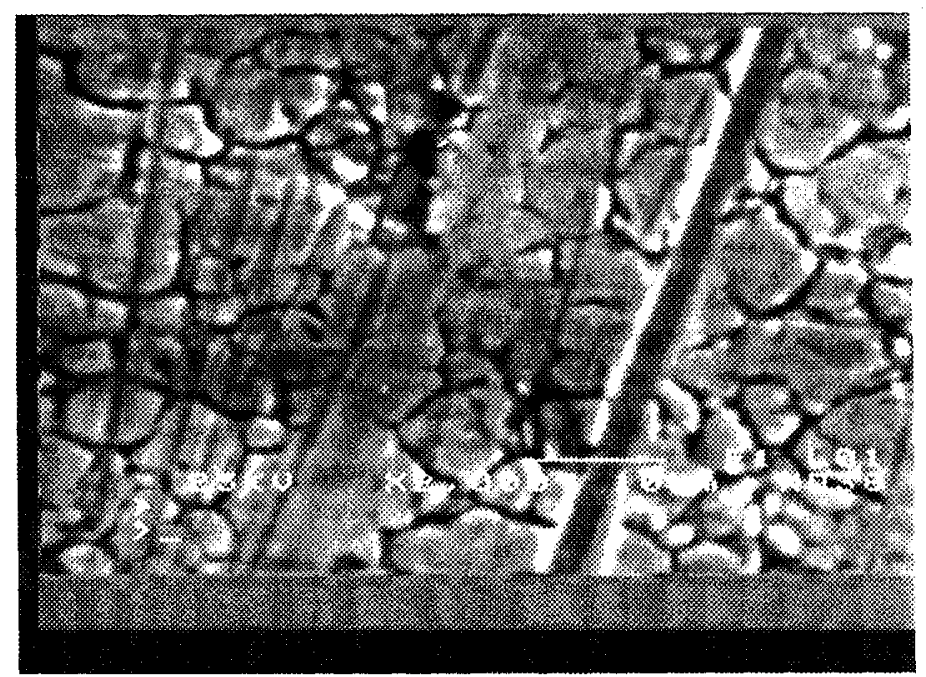

FIGURE 5 SEM photograph of ZnO film surface.

\section{METHODS FOR MEASURING THE PIEZOELECTRIC PROPERTIES}

\subsection{Static Methods}

In general the electrical properties of a piezoelectric material in thin form can be determined by static methods and dynamic ones. Static methods $[23,24]$ are straight forward to use. Using the direct piezoelectric effect (dp) by applying a stress and measuring the induced charge (or voltage), or by use of the inverse piezoelectric effect (ip), i.e., applying a voltage (electric field) and measuring the induced elongation (strain). In principle, both methods allow to measure the piezoelectric coefficient $d_{33}$ called charge constant. It is defined by:

$$
d_{33}=\left(\frac{\partial S_{3}}{\partial E_{3}}\right)_{T} \quad \text { or } \quad d_{33}=\left(\frac{\partial D_{3}}{\partial T_{3}}\right)_{E}
$$

where $S$ is the strain, $E$ the electric field, $D$ the electric displacement, and $T$ the stress in the appropriate direction.

In the normal load method, a weight is applied on an area $A$ of the piezoelectric film and the induced charge, stored in a capacitor 
connected across the piezoelectric device, is measured. The accuracy of this method is limited by electric leakage through the capacitors (leading to a decrease of the induced charge) and by electric noise. However, the method can be very easily implemented to determine $d_{33}$ (ip) of thin films.

A high input impedance voltmeter was needed to measure the voltage over the capacitor. It was checked that the piezoelectric effect was reversible, i.e., that increasing or decreasing the force led to opposite voltages. It was also verified that the induced voltage increased linearly with force and $d_{33}$ was calculated from the slope of this line. This linear relationship conforms to the piezoelectric theory since the measurements were done in the low signals region (stress less than $20 \mathrm{MPa}$ ).

The use of aforementioned static methods gave us an easy tool to make preliminary comparative studies between samples prepared at different deposition conditions in order to discover the optimum deposition conditions required for the $\mathrm{ZnO}$ thin films.

\subsection{Dynamic Methods}

Consequently, a dynamic method was employed in order to study the potential of $\mathrm{ZnO}$ films for the fabrication of high frequency filters. The most important parameter for thin piezoelectric film high frequency applications is the electromechanical coupling factor $K^{2}$. The calculation of this term from material piezoelectric elastic and dielectric parameters varies for different film excitation and boundary conditions. The bandwidth of piezoelectric filters and transducers is dependent upon the appropriate coupling factor. Different materials can directly be compared for the same application from their coupling factors without knowledge of their sets of elastic dielectric and piezoelectric constants [25]. In high frequency filters ( $\mathrm{GHz}$ range) the thickness of the film is only a few microns with much larger lateral dimensions so a film supporting structure is required. The film with the necessary electrodes and the supporting substrate form a composite structure known as overmoded resonator with the substrate acoustic properties (mechanical impedance, acoustic losses and surface finish) strongly affecting the measurements of thin film parameters. The one dimensional theory [26] gives the electrical impedance between the 
electrodes as:

$$
\begin{aligned}
Z_{\text {in }}=\frac{1}{j \omega C}[ & 1-\frac{K^{2}}{1+K^{2}} \frac{\tan \theta}{\theta} \\
& \left.\cdot \frac{\left(z_{\text {above }}-z_{\text {below }}\right) \cos ^{2} \theta+j \cdot \sin (2 \cdot \theta)}{\left(z_{\text {above }}-z_{\text {below }}\right) \cos (2 \cdot \theta)+j\left(1-z_{\text {above }} \cdot z_{\text {below }}\right) \sin (2 \cdot \theta)}\right]
\end{aligned}
$$

with the electromechanical coupling factor defined as:

$$
K^{2}=\frac{e^{2}}{c^{E} \varepsilon^{S}}
$$

where $e, c^{E}$, and $\varepsilon^{S}$ are the piezoelectric stress constant, stiffness constant at constant $E$ and dielectric constant at constant strain respectively.

$$
\theta=\frac{k d}{2}
$$

is half the phase delay in the piezoelectric layer and $z_{\text {above, }}, z_{\text {below }}$, are the mechanical input impedances above and below the piezoelectric film respectively normalised with the mechanical impedance $Z_{\mathrm{p}}$ of piezoelectric film. At each material interface the input impedance is calculated using a transmission line model. For example the input impedance at the interface piezoelectric film/bottom $\mathrm{Zn}$ electrode is:

$$
Z_{\text {in }, \mathrm{Zn}}=Z_{\mathrm{Zn}}\left(\frac{Z_{\mathrm{in}, \mathrm{Si}} \cos (-\vartheta)+j Z_{\mathrm{Zn}} \sin (-\vartheta)}{Z_{\mathrm{Zn}} \cos (-\vartheta)+j Z_{\mathrm{in}, \mathrm{Si}} \sin (-\vartheta)}\right)
$$

where $Z_{\mathbf{z n}}$ is the Zinc characteristic impedance $Z_{\mathrm{in}, \mathrm{Si}}$ the input mechanical impedance at the Zinc/Silicon interface and $\vartheta$ the phase delay in the bottom electrode. The theory does not take account of acoustic wave diffraction taking place inside the substrate giving substantial additional losses. In the input electrical impedance formula the effect of the electrodes (thickness $<0.3 \mu \mathrm{m}$ ) is usually neglected and the losses are mainly due to wave propagation in the much thicker substrate. Losses can be introduced through a complex material stiffness

$$
c=c_{\text {real }}+2 \pi f \eta
$$


where $f$ is the frequency and $\eta$ the acoustic viscosity. The Sitting's model [27] of a piezoelectric transducer attached between a backing and a transmitting medium can also be used to obtain the same relation for input impedance given by Eq. (2).

A simulated electrical input impedance for an overmoded resonator on a $\{100\}$ silicon substrate is given in Figures $6(a)-(c)$ with data in Table II.

The equation describing an ideal thin film resonator electrical input impedance is a good reference for understanding the overmoded resonator:

$$
Z_{\text {ideal, TFR }}=\frac{1}{j \omega C}\left[1-\frac{K^{2}}{K^{2}+1} \frac{\tan \varphi}{\varphi}\right]
$$

where $C$ is again the clamped capacitance $K^{2}$ the coupling factor and $\varphi$ the half the phase delay in the piezoelectric film. In the above relation the electrodes are ideal, with zero thickness and

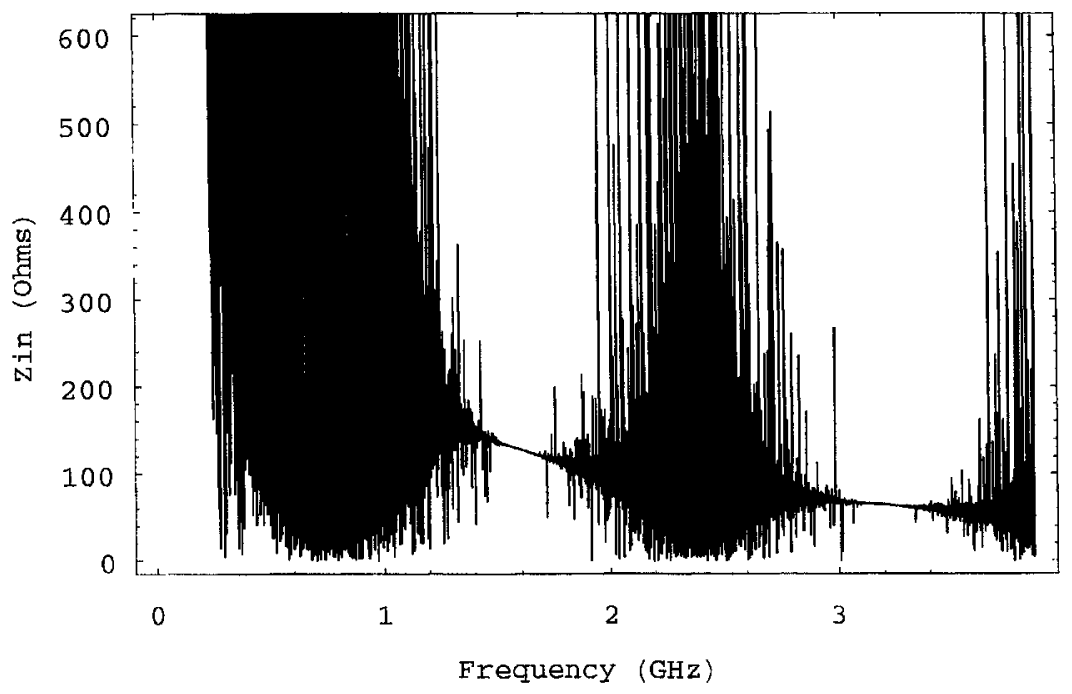

(a)

FIGURE 6 Simulated response for an overmoded resonator based on the data from Table II. (a) Broad band impedance magnitude, (b) Impedance magnitude near a single resonance, (c) phase response for (b), and (d) ideal TFR's impedance magnitude. 


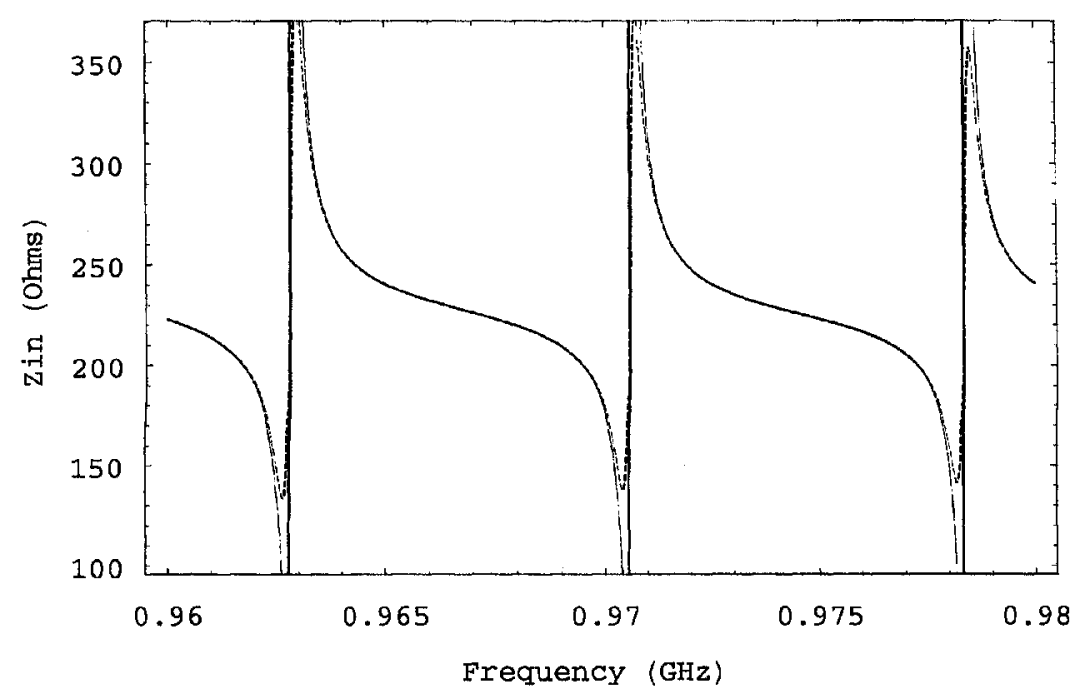

(b)

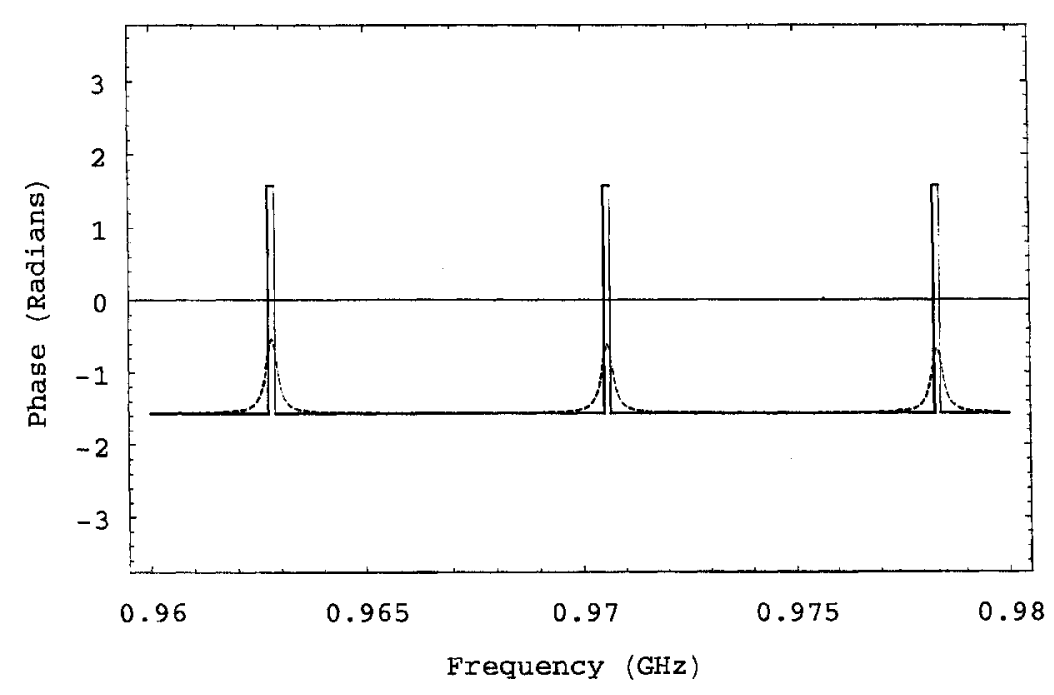

(c)

FIGURE 6 (Continued).

$Z_{\text {above }}=Z_{\text {below }}=0$. Comparing Eq. (2) with Eq. (7) we see that Eq. (2) contains Eq. (7) so the overmoded resonator response is a modulated ideal resonator response with substrate introducing a 


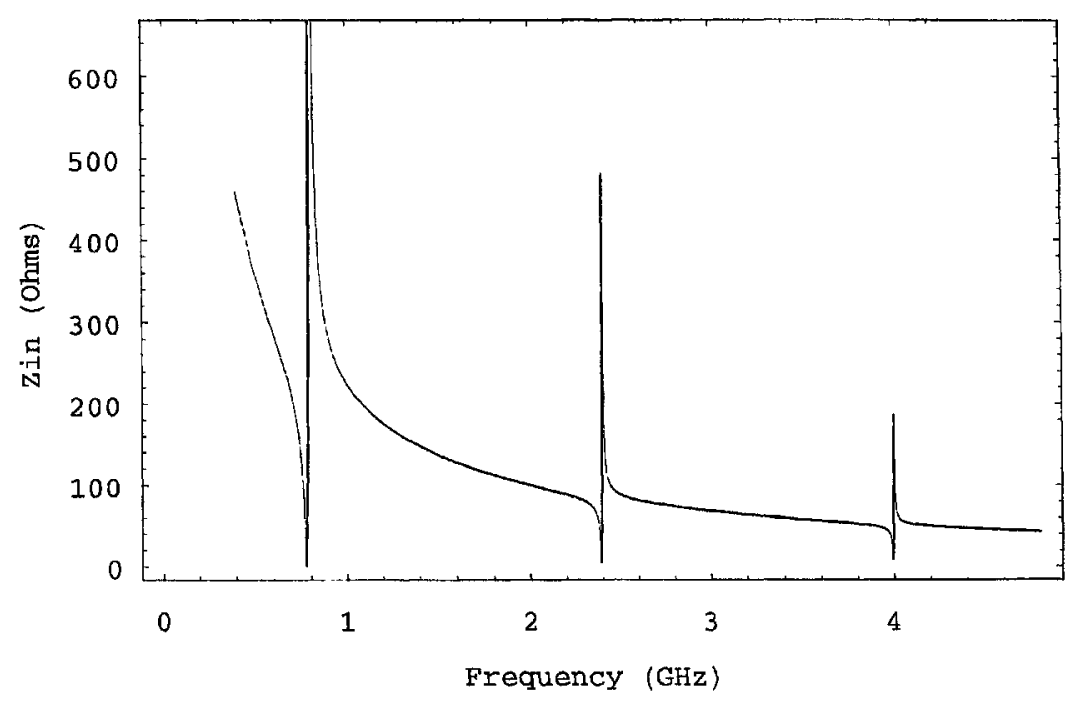

(d)

FIGURE 6 (Continued).

TABLE II Data for the simulated response of an overmoded resonator seen in Figure 6

\begin{tabular}{lccccc}
\hline & $\begin{array}{c}\text { Thickness } \\
l_{i} \\
(\mu \mathrm{m})\end{array}$ & $\begin{array}{c}\text { Density } \\
\rho_{i} \\
\left(\mathrm{Kgr} / \mathrm{m}^{3}\right)\end{array}$ & $\begin{array}{c}\text { Stiffness } \\
\left(\mathrm{Nt} / \mathrm{m}^{2} \times 10^{9}\right)\end{array}$ & $\begin{array}{c}\text { Viscosity } \\
n \\
\left((\mathrm{Nt} \cdot \mathrm{sec}) / \mathrm{m}^{2}\right)\end{array}$ & \multicolumn{1}{c}{ Comments } \\
\hline ZnO & 4.0 & 5675 & 232.5 & - & $\begin{array}{l}\text { The solid line in } \\
\text { Figure } 6 \text { is with }\end{array}$ \\
$\mathrm{Si}\{001\}$ & 540 & 2332 & 165.7 & 0.008 & $\begin{array}{l}\text { Si } n=0 \text { and } \\
\text { the dashed with } \\
n=0.008\end{array}$ \\
\hline
\end{tabular}

multiplicity of short spaced resonances on the wide separated and few of the ideal thin film resonator also seen in Figure 6(d).

Each resonance seen in Figure 6(b) can be quantified by two figures of merit $k_{\text {eff }}^{2}$ the effective coupling constant and $Q$ the quality factor.

These are defined as:

$$
\begin{gathered}
k_{\mathrm{eff}}^{2}=\frac{(\pi / 2)\left(f_{s} / f_{p}\right)}{\tan \left((\pi / 2)\left(f_{s} / f_{p}\right)\right)} \\
Q=\left.\frac{f_{s}}{2} \frac{\partial L Z}{\partial f}\right|_{f_{s}}
\end{gathered}
$$


where $f_{s}, f_{p}$ are the frequencies at which the magnitude of impedance is minimum and maximum respectively.

The first term $k_{\text {eff }}^{2}$, is a strong function of the electromechanical coupling factor $K^{2}, Q$ is independent of $k_{\text {eff }}^{2}$ and expresses the material losses. Because the overmoded resonator suffers from excess loss the calculation of these terms directly from the measured response is inaccurate. On the contrary for low loss resonators such as crystal resonators in the $\mathrm{MHz}$ range the above equations are directly applicable.

\subsection{The BVD Model}

A method for indirectly obtaining the aforementioned figures of merit is described in [28]. It is based on the the Butterworth-Van Dyke (BVD) equivalent circuit (Fig. 7). The electrical input impedance of the BVD circuit is calculated as:

$$
Z=\left(\frac{1}{j \omega\left(C_{1}+C_{2}\right)}\right) \frac{1-\left(f / f_{s}\right)^{2}+\left(j / Q_{s}\right)\left(f / f_{s}\right)^{2}}{1-\left(f / f_{p}\right)^{2}+\left(j / Q_{p}\right)\left(f / f_{p}\right)^{2}}
$$

with

$f_{s}=\frac{1}{2 \pi} \sqrt{\frac{1}{L C_{1}}}, \quad f_{p}=\frac{1}{2 \pi} \sqrt{\frac{C_{1}+C_{2}}{L C_{1} C_{2}}},\left.\quad Q_{\mathrm{BVD}}\right|_{s, p}=\frac{2 \pi f_{s, p} L}{R}$

In the neighbourhood of a single resonance of the overmoded resonator its response is similar to the response of the BVD circuit shown in Figure 7. By varying the parameters of the BVD circuit we can fit the two responses. At the condition of best fit according to some

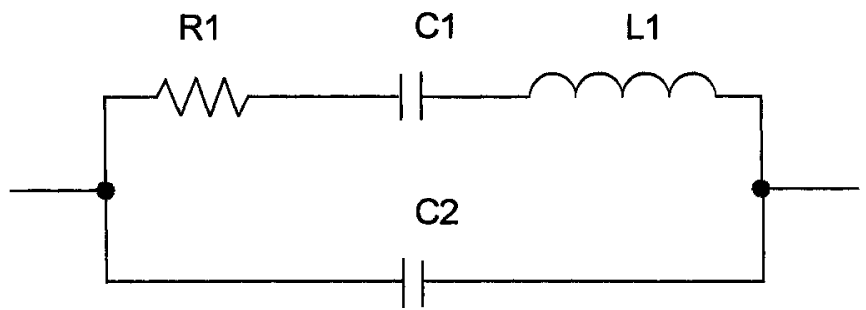

FIGURE 7 The electrical equivalent circuit for the BVD model of a lossy resonator. 
cost criterion (such as least squares) we use the BVD circuit element values for the calculation of piezoelectric film's figures of merit. The $k_{\text {eff }}^{2}$ of the resonator is calculated from the $f_{s}, f_{p}$ of the BVD model and Eq. (7). In the model two values $Q_{s}$ and $Q_{p}$ for the quality factor appear. These values approach a common value as frequency increases. The fitting of the two responses can be done either from phase or magnitude data but it was found that phase fitting gives better results.

\section{EXPERIMENTAL RESULTS FROM THE RESONATORS}

\subsection{Measuring Techniques}

All measurements were done on an HP8753D network analyser and a home-made microwave probe station at different temperatures. Silicon wafers having nominal thicknesses of $540 \mu \mathrm{m}$ optically polished in one side were used as substrates. $\mathrm{Zn} / \mathrm{ZnO} / \mathrm{Zn}$ structures were tested being fabricated on both the polished and the rough wafer face. The resonators consisted of zinc oxide $c$-axis normal films with circular electrodes of $\sim 0.3 \mu \mathrm{m}$ thick zinc as shown in Figure 1. The $\mathrm{ZnO}$ thickness was calculated to induce resonance in the center of the frequency range of interest for maximum excitation efficiency. Silicon was chosen as the primary substrate material during these initial investigations because of its known high $Q$ and ready availability in optically polished wafers. Glass substrates with nominal thickness $150 \mu \mathrm{m}$ were also used, but with surface parallelism inferior to the silicon substrates. Also due to amorphous nature of glass material losses were much higher giving very weak resonator responses.

The calculated $Q_{s}, Q_{p}$ and $K_{\text {eff }}^{2}$ are tabulated in Table III for polished and unpolished $\mathrm{Si}$ wafer backside at different deposition temperatures. The XRD results for these films are given in Figures $2-4$, respectively.

\subsection{Effective Piezoelectric Coupling Factor}

The first observation is that the substrate surface roughness affects the coupling factor with much lower coupling factor for deposition in a 


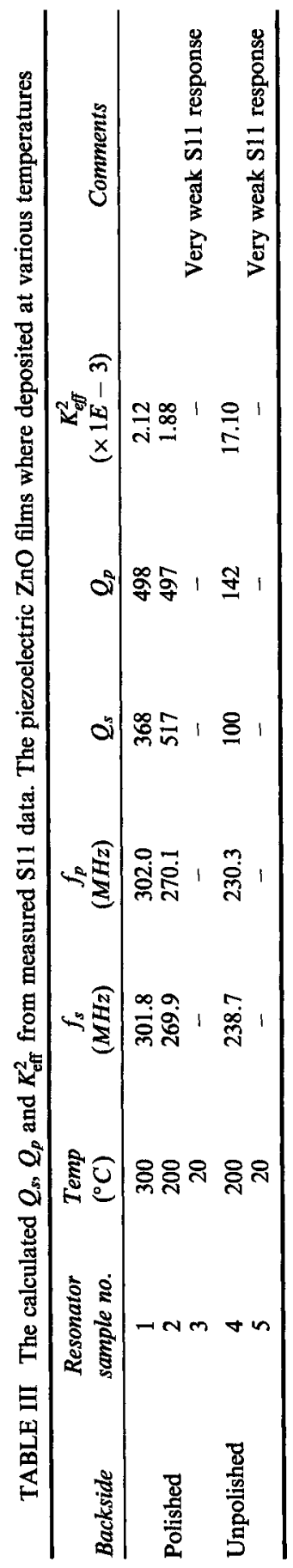


rough surface. This is seen by comparing the $200^{\circ} \mathrm{C}$ temp $K_{\text {eff }}^{2}$ data on Table III on a polished and unpolished surface wafer.

The network analyser measurements verify that the resonators present maximum performance at substrate temperature of $200^{\circ} \mathrm{C}$. From Table III one can see that the calculated $K_{\text {eff }}^{2}$ is an order of magnitude greater for these films. This was expected because films, deposited at $200^{\circ} \mathrm{C}$ temperature, feature only a strong $\{002\}$ preferred orientation. On the other hand for higher deposition temperatures $\left(300^{\circ} \mathrm{C}\right)$ the $\{101\}$ orientation becomes relative strong reducing $K_{\text {eff }}^{2}$ and inducing spurious resonances observed for small lateral dimension resonators. For film deposition at room temperature the films show many crystallographic orientations of the same small size verified by the weak and full of spurious S11 network analyzer rmeasurements.

\subsection{Quality Factor}

The overmoded resonator quality factor $Q_{s}, Q_{p}$ calculated from the experimental results depends strongly on the finish of wafer backside and it is independent of piezoelectric film's coupling factor. This is expected because acoustic scattering in an unpolished wafer backside reduces greatly the energy reflected toward the piezoelectric transducer lowering the $Q$ of the device. The rest of the scattered energy is attenuated inside the Si wafer.

Spurious resonances were observed and become very pronounced if the overall structure, including the device, had nonparallel surfaces or the lateral dimensions of the resonator were relatively small. Also in the high temperature samples the non perfect film orientation with the strong $\{101\}$ peak induced spurious resonances who where cancelled out in larger lateral dimensions resonators.

\subsection{Working Temperature Effects}

The "best" of the above resonators were tested at various temperatures. S11 plot versus frequency for mode number 34 and 35 at temperatures 30 and $100^{\circ} \mathrm{C}$ is shown in Figure 8.

The results for mode number 35 are tabulated in Table IV. As seen the calculated $f_{s}, f_{p}$ varies slightly with temperature. The temperature coefficient which is of the order of $-30 \mathrm{ppm} /{ }^{\circ} \mathrm{C}$ comparable with the 


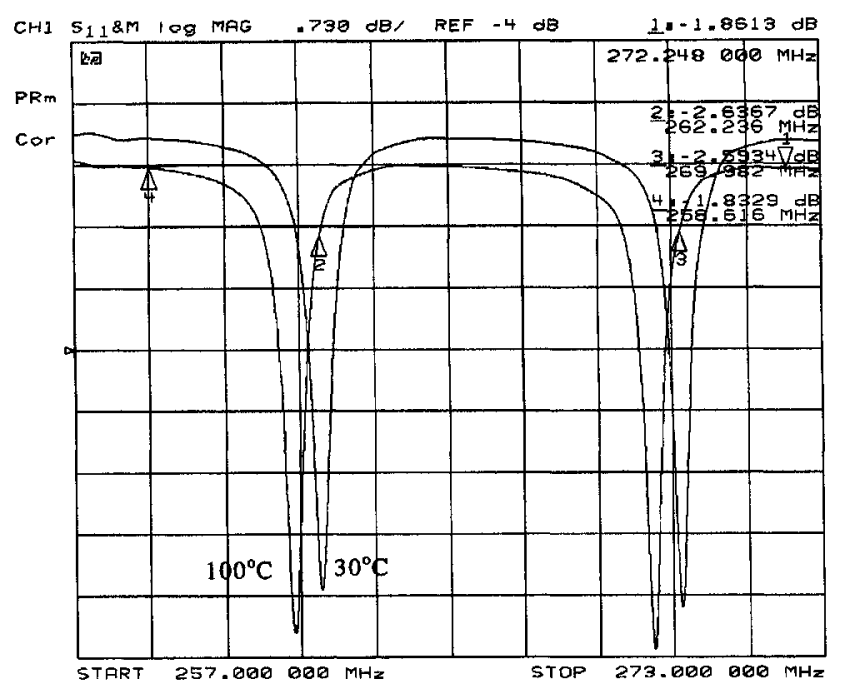

FIGURE 8 Overmoded resonator $\mathrm{S} 11$ response at $30^{\circ} \mathrm{C}$ and $100^{\circ} \mathrm{C}$.

TABLE IV The calculated figures of merit at various temperatures for an $\mathrm{ZnO}$ overmoded resonator

\begin{tabular}{lccccc}
\hline $\begin{array}{l}\text { Temp } \\
\left({ }^{\circ} \mathrm{C}\right)\end{array}$ & $\begin{array}{c}f_{s} \\
(M H z)\end{array}$ & $\begin{array}{c}f_{p} \\
(M H z)\end{array}$ & $Q_{s}$ & $Q_{p}$ & $\begin{array}{c}k_{\text {eff }}^{2} \\
\left(\times 10^{-3}\right)\end{array}$ \\
\hline 30 & 269.87 & 270.11 & 456 & 466 & 2.107 \\
100 & 269.29 & 269.54 & 450 & 448 & 2.273 \\
Temp coefficient $\left(\mathrm{ppm} /{ }^{\circ} \mathrm{C}\right)$ & -30.8 & -30.2 & -189.2 & -252.8 & 270.1 \\
\hline
\end{tabular}

thermal coefficient of expansion in the order of $10-15 \mathrm{ppm} /{ }^{\circ} \mathrm{C}$ for most materials. This suggests that thermal expansion is the main reason for temperature variation. Also small changes in materials elastic parameters with temperature may contribute to the above change.

It is also interesting to note that the $Q$ of the device drops with temperature. This is attributed to the Akhieser mechanism [28] which predicts a very linear relation between the material attenuation factor $\alpha$ and working temperature. Finally, the observed increase of $K_{\mathrm{eff}}^{2}$ with working temperature is due to thermal expansion of the piezoelectric layer. As its thickness approaches the $\lambda / 2$ value where $\lambda$ is the piezoelectric material's acoustic wave length at the specified frequency the coupling between the electromagnetic and acoustic fields 
becomes maximum thus $K_{\text {eff }}^{2}$ increases. However, if piezoelectric layer's thickness was larger than $\lambda / 2$ a reduction with temperature would be observed.

\section{CONCLUSIONS}

The results of the present study show that reactively sputtered $\mathrm{ZnO}$ thin films are very good candidates for the construction of overmoded TFR filters to be used at the RF part of the spectrum. To this contribute the easiness of deposition of highly oriented films and the repeatability of the process together with the recorded low temperature drift that does not exceed, in our case the value of $-30 \mathrm{ppm} /{ }^{\circ} \mathrm{C}$.

The quality factor $Q$, of our devices is close to 1000 without any attempt to increase it further, by the use possibly of a Bragg acoustic reflector, since it was outside the scope of this work.

It is expected that the use of several devices, as the ones studied in this work, in a ladder interconnection and with the proper $\mathrm{ZnO}$ thickness will allow the construction of tailored bandpass overmoded filters.

\section{References}

[1] Itoh, T. and Suga, T. (1993). Development of a force sensor for atomic force microscopy using piezoelectric thin films, Nanotechnology, 4, 218-224.

[2] Deschanvres, J. L., Rey, P., Delabot glise, G., Labeau, M., Joubert, J. C. and Peuzin, J. C. (1992). Characterization of piezoelectric properties of zinc oxide thin films deposited on silicon for sensors applications, Sensors and Actuators $A, 33$, $43-45$.

[3] Blom, F. R., Yntema, D. J., Van de Pol, F. C. M., Elwenspoek, M., Fluitman, J. H. J. and Popma, Th. J. A. (1990). Thin-film ZnO as micromechanical actuator at low frequencies, Sensors and Activators, A21, A23, 226-228.

[4] Motamedi, M. E. (1994). Micro-opto-electro-mechanical systems, Opr. Erg., 33, 3505-3517.

[5] Judy, J., Polla, D. L. and Robbins, W. P. (1990). A linearpiezoelectric stepper motor with sub-micron step size and centimeter travel range, IEEE Trans. Ultrasonics, Ferroelectrics Freq. Control, 37, 428-437.

[6] Tominanga, T., Ohya, N., Senda, K., Idogaki, T. and Hattori, T., Flexible stacked type actuators, Proc. 5th Int. Sytnp. Micro Machine and Hctman Science (IEEE) 1994, pp. 143-147.

[7] Miyazaki, H., Kameya, T., Sato, T., Hatamura, Y. and Morishita, H., Construction of an ultra-micro manipulation system based on visual controlrealisation of nano-hand-eye system, IEEE Symp. Emerging Technologies Factory Autornation 1994, pp. 74-77. 
[8] Menz, W. (1993). Three-dimensional microstructures in various materials for medical applications, Int. Conf. Systems, Man and Cybernetics, pp. 417-422.

[9] Cunningham, M. J., Cheng, S. T. and Clegg, W. W. (1994). A differential interferometer for scanning force microscopy, Meas. Sci. Technol., 5, 1350-1354.

[10] Kiyotaka Wasa and Shigeru Hayakawa (1992). Handbook of sputter deposition technology, Noyes Publications, pp. 135-155.

[11] Jenkins, D. F. L., Cunningham, M. J. and Clegg, W. W., The use of piezoelectric films for actuation and control of miniature cantilevers, presented at 1 st Eur. Meet. Integrated Ferroelectrics, Nijmegen, Netherlands, July, 1995, Microelectronic Eng., 29, $71-74$.

[12] McKinstry, S. T., Fox, G. R., Kholkin, A., Muller, C. A. and Setter, N. (1999). Optical fibers with patterned $\mathrm{ZnO}$ electrode coatings for flexural actuators, Sensors and Actuators, 73, 267-274.

[13] Shiosaki, T. and Kawabata, A. (1974). Low-frequency piezoelectric transducer applications of $\mathrm{ZnO}$ film, Appl. Phys. Lett., 25, 10.

[14] Ono, S., Wasa, K. and Hayakawa, S. (1977). Surface acoustic-wave properties in ZnO-SiOz-Si layered structure, Wave Electron., 3, 35.

[15] Clark T.-C. Nguyen, Linda P. B. Katehi and Gabriel M. Rebeiz, Micromachined Devices for Wireless Communications, Proceedings of the IEEE, August, 1998, 86(8), 1756-1767.

[16] Tsiogas, C. D. and Avaritsiotis, J. N., Practical aspects for the use of plasma emission monitoring in reactive magnetron sputtering, April, 1994, Vacuum, 45(4), $1181-1186$.

[17] Krupanadhi, S. B. and Sayer, M. (1984). Position and pressure effects in r.f. magnetron reactive sputter deposition of piezoelectric zinc oxide, J. Appl. Phys., 56, $3308-3312$.

[18] Kmpanidhi, S. B., Sayer, M., Assal, K. E., Jen, C. K. and Farrel, G. W. (1984). Fabrication and characterisation of piezoelectric films for SAW and acoustic microscopy, J. Can. Cerarn. Soc., 53, $28-33$.

[19] Mitsuyu, T., Ono, S. and Wasa, I. C. (1980). Structures and SAW properties of R.F. sputtered single crystal films of $\mathrm{ZnO}$ on saphire, J. Appl. Phys., 51, 2464-2470.

[20] Barker, A., Crowther, S. and Rees, D. (1997). Room-temperature r.f. sputtered $\mathrm{ZnO}$ for electromechanical devices, Sensor and Actuators, A58, 229-235.

[21] Jenkins, D. F., Cunningham, M. J., Velu, G. and Remiens, D. (1997). The use of sputtered $\mathrm{ZnO}$ piezoelectric thin films as broad-band microactuators, Sensors and Actuators, A63, 135-139.

[22] Yoon, K. H., Choi, J. W. and Lee, D. H. (1997). Characteristics of ZnO thin films deposited onto $\mathrm{Al} / \mathrm{Si}$ substrates by RF magnetron sputtering, Thin Solid Films, 302, $116-121$.

[23] Lefki, K. and Dormans, G. J. (1994). Measurement of piezoelectric coefficients of ferroelectric thin films, J. Appl. Phys., 76(3), 1764-1767.

[24] Kim, D., Method and apparatus for measuring the piezoelectric constant of a thin film type piezoelectric material, International Patent Application WO98/25150, 11 June, 1998.

[25] Mason, W. P. (1964). Physical Acoustics Principles and Methods, Vol. I, part A, Chapter 3, pp. 190-196, Academic Press.

[26] Rajan S. Naik, Lutsky, J. J., Reif, R. and Sodini, Ch. G., Electromechanical Coupling Constant Extraction of Thin-Film Piezoelectric Materials Using a Bulk Acoustic Wave, Jan., 1998, Resonator IEEE Trans. Ultras. Ferroel. and Freq. Control, 45(1), 257-263.

[27] Mason, W. P. and Thurston, R. N. (1972). Physical Acoustics Principles and Methods, Vol. XI, Chapter 5, Academic Press.

[28] Rajan S. Naik, Bragg Reflector thin film resonators for miniature PCS bandpass filters, Ph.D. Thesis, Dept. of Electrical Engineering and Computer Science, Massachusetts Institute of Technology, Cambridge MA, 1998. 
[29] Lutsky, J. J., A sealed cavity thin film acoustic resonator process for RF bandpass filters, Ph.D. Thesis, Dept. of Electrical Engineering and Computer Science, Massachusetts Institute of Technology, Cambridge MA, 1997.

[30] Auld, B. A., "Acoustic fields and waves in solids", Vols. 1 and 2, Academic Press, 1990. 

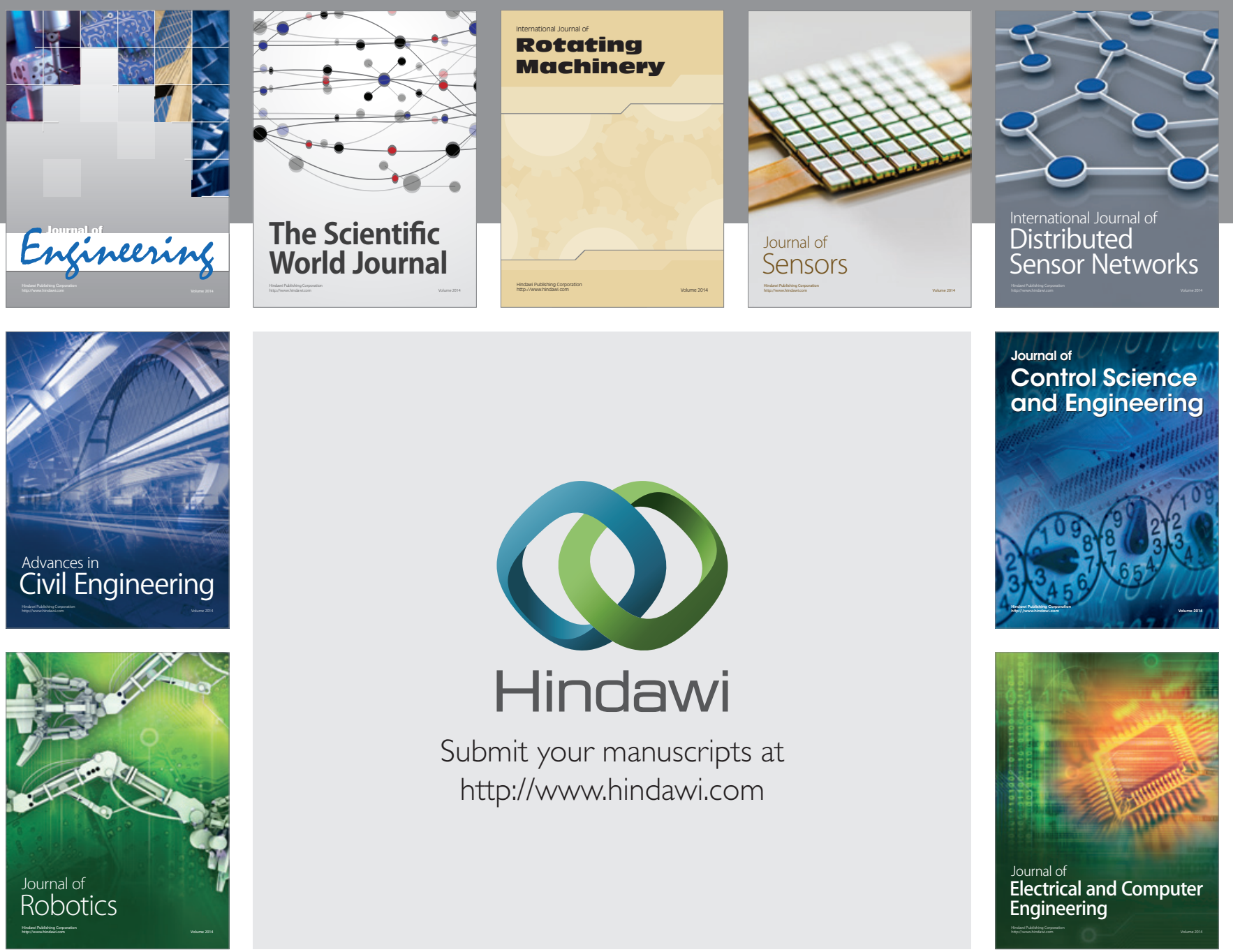

Submit your manuscripts at

http://www.hindawi.com
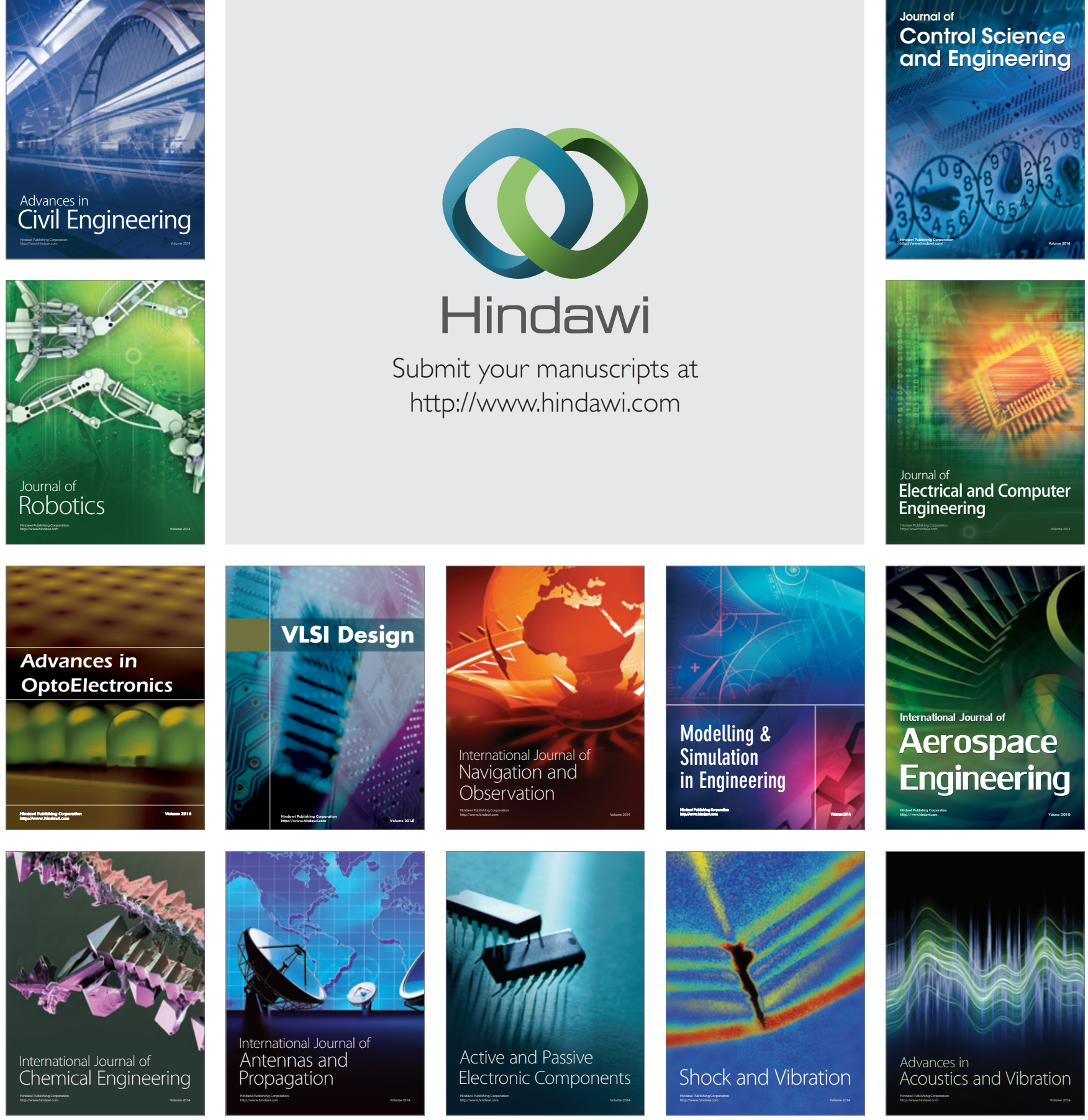